\title{
Pediatric case of acute right-sided abdominal pain: diagnosis is not always appendicitis
}

This article was published in the following Dove Press journal:

Pediatric Health, Medicine and Therapeutics

8 June 2017

Number of times this article has been viewed

\section{Fawzia Elgharbawy' \\ Khalil Salameh' \\ Talal Al Rayes ${ }^{2}$ \\ Ibtihal S Abdelgadir ${ }^{3}$}

'Pediatrics Division, Al Wakra Hospital, ${ }^{2}$ Hamad Medical Corporation, ${ }^{3}$ Sidra Medical and

Research Centre, Doha, Qatar
Correspondence: Khalil Salameh Pediatrics Division, AI Wakra Hospital, Hamad Medical Corporation, Al Wakair Street \# I, Doha III, Qatar

Tel +974 40I I 4257

Email ksalameh@hamad.qa
Abstract: Omental infarction (OI) is a rare cause of acute abdominal pain occurring in $0.1 \%$ of children, which is typically diagnosed during surgery for suspected appendicitis. We present the case of a 7-year-old Pakistani girl. She presented with acute, severe, progressive, right-sided abdominal pain, which was present for 12 hours before presentation. No constitutional symptoms such as fever, anorexia, nausea or vomiting were present. Clinical examination revealed an adequately growing child following the 50th centile. She had severe generalized abdominal tenderness with rebound tenderness and guarding, mainly on the right lower abdominal quadrant, with all other system examinations normal. She had mildly increased inflammatory markers, and her initial abdominal ultrasound scan result was within normal limits. She had laparoscopic surgery following a diagnosis of suspected acute appendicitis; however, an intraoperative diagnosis of OI was made. This was later confirmed by histopathology. This case report highlights the importance of including OI in the differential diagnosis list of acute abdominal pain in children, in addition to the importance of computed tomography (CT) as the gold standard tool to aid diagnosis. In the presence of typical symptoms and signs of OI, a CT scan can assist and guide the management of similar cases. This course of action is suggested for the reason that OI typically runs a self-limited course and conservative care may be the most appropriate recommended course of action. Consequently, unnecessary operations could be avoided due to the diagnosis confirmation of studying images.

Keywords: omentum, infarction, abdominal pain, child

\section{Introduction}

Omentum is a fat-laden peritoneal fold located just anterior to the transverse colon, where progressive perivascular fat deposition and extension occur throughout childhood, and it is anatomically divided into the greater and lesser omentum. ${ }^{1,2}$

Omental infarction (OI) is an uncommon cause of acute abdominal pain occurring in $\sim 0.1 \%$ of children who undergo laparotomy for suspected appendicitis. ${ }^{1,3,4}$ It can cause acute abdominal pain in several different locations. ${ }^{5}$ Multiple etiological factors have been associated with OI. Here, we report a clinical case of OI who was diagnosed during laparoscopic surgery for suspected appendicitis and who was successfully managed.

\section{Case report}

A 7-year-old girl was presented to the pediatric emergency department with a sudden onset of progressive abdominal pain lasting for 12 hours prior to presentation. No fever, nausea or vomiting was present, and normal bowel habits were determined. No 
urinary symptoms were present, and there were no recurrent abdominal pain.

The pain was located more to the right iliac fossa and was associated with tenderness, rebound tenderness and guarding. She was adequately growing in accordance to the 50th centile for weight and height.

Laboratory findings included leukocytosis (white blood cell count of $15.4 \times 109 / \mathrm{L}$ with $76.5 \%$ neutrophils) and an elevated C-reactive protein level $(24 \mathrm{mg} / \mathrm{L})$.

Considering the differential acute abdominal pain, an abdominal ultrasound (US) was requested and was reported as normal.

A pediatric surgeon reviewed and observed the child; however, the clinical picture persisted despite adequate conservative management and analgesia. As a consequence, the decision was made to perform laparoscopic appendectomy surgery with the consideration of acute appendicitis being the likely cause.

The intraoperative findings were a normal looking appendix and infarcted omentum in the right upper quadrant adherent to the liver. This was confirmed following a histopathology report.

The child was discharged home after 12 hours; however, she subsequently represented with a wound infection as a postsurgical complication and was treated accordingly. She remained well after discharge.

\section{Consent}

Written informed consent was obtained from the father of the child for publication of this case report and accompanying images.

\section{Discussion}

$\mathrm{OI}$ is a rare condition that occurs mainly in adults in their fourth and fifth decades. The incidence is equivalent to $<4$ cases/1000 cases of appendicitis. ${ }^{2,6}$ Conversely, in childhood, OI is frequently overlooked as a cause of acute abdominal pain. Consequently, the diagnosis is almost always made during surgery for suspected appendicitis. . $^{2,3,6-11,13}$

A conservative approach may be more appropriate for OI management, if an accurate diagnosis is viable before surgery. ${ }^{1}$ This is in addition to and under careful consideration of the potential morbidity and mortality with potentially missed cases. $^{12}$

The diagnosis of OI should be suspected in particular clinical presentations. There are some suggestive features of OI such as obesity, persistent right-sided abdominal pain, absence of fever and a normal white cell count. ${ }^{1,2}$ Torsion and infarction occur generally around the distal right epiploic artery, resulting in right-sided abdominal pain. The infarcted omentum could be due to primary causes or, alternatively, secondary to multiple risk factors, including malformations of the omental pedicle, sudden increase in intra-abdominal pressure, abnormal clotting, the presence of a hernia, tumors and/or adhesions. ${ }^{1,2,7}$

A typical appendicitis, which is a clinical picture of rightsided persistent abdominal pain and low-grade or absent fever, with no digestive symptoms and no anorexia, which is present in a well-being yet most often obese child should lead to consideration of a diagnosis of OI. ${ }^{2,6,7,9}$

Upon abdominal examination in OI cases, there is tenderness and, occasionally, a mass is palpable in the right quadrant. Laboratory data typically reveal normal or slightly increased leukocyte count and C-reactive protein. ${ }^{1,2,7,9}$

The diagnosis is confirmed with imaging techniques. Abdominal US scans have low sensitivity with regard to the confirmation of diagnosis, but may raise the suspicion. ${ }^{9} \mathrm{Com}-$ puted tomography (CT) is the "gold standard" investigation, which reveals a large, cake-like, high-attenuation fatty mass centered in the omentum when it is infracted. ${ }^{11,13,14}$

The management of OI is still controversial. Some surgeons favor the operative treatment, either open or laparoscopic; ${ }^{2,6-8,10}$ others however believe that the conservative approach is advantageous, as OI is a self-limited entity with prompt resolution of symptoms and total regression without complications. ${ }^{1,13}$ However, no comparative study demonstrates a significant difference in outcome following surgery and conservative treatment. ${ }^{3,13,15}$

\section{Conclusion}

Diagnosis of OI in children is challenging. In our case study, we highlight $\mathrm{OI}$ as one of the differential diagnoses of acute abdominal pain in children, in addition to the necessity of CT with suspected OI, even if the US result is negative or inconclusive.

Further studies in the diagnosis and management of OI are needed.

\section{Disclosure}

The authors report no conflicts of interest in this work.

\section{References}

1. Fragoso AC, Pereira JM, Estevão-Costa J. Nonoperative management of omental infarction: a case report in a child. J Pediatr Surg. 2006;41(10):1777-1779.

2. Helmrath MA, Dorfman SR, Minifee PK, Bloss RS, Brandt ML, DeBakey ME. Right lower quadrant pain in children caused by omental infarction. Am J Surg. 2001;182(6):729-732. 
3. Agresta F, Bedin N. Primary omental infarction: laparoscopic approach in two pediatric cases: a case review. J Laparoendosc Adv Surg Tech A. 2007;17(6):831-832.

4. Houben $\mathrm{CH}$, Powis M, Wright VM. Segmental infarction of the omentum: a difficult diagnosis. Eur J Pediatr Surg. 2003;13(1):57-59.

5. Park TU, Oh JH, Chang IT, et al. Omental infarction: case series and review of the literature. J Emerg Med. 2012;42(2):149-154.

6. Varjavandi V, Lessin M, Kooros K, Fusunyan R, McCauley R, Gilchrist B. Omental infarction: risk factors in children. J Pediatr Surg. 2003;38(2):233-235.

7. Loh $\mathrm{MH}$, Chui $\mathrm{CH}$, Yap T, et al. Omental infarction - a mimicker of acute appendicitis in children. J Pediatr Surg. 2005;40(8):1224-1226.

8. Nagar H, Kessler A, Ben-Sira L, Klepikov I, Wiess J, Graif M. Omental infarction: an unusual cause of acute abdomen in children. Pediatr Surg Int. 2003;19(9-10):677-679.

9. Schlesinger AE, Dorfman SR, Braverman RM. Sonographic appearance of omental infarction in children. Pediatr Radiol. 1999;29(8):598.
10. Pereira JM, Sirlin CB, Pinto PS, Jeffrey RB, Stella DL, Casola G. Disproportionate fat stranding: a helpful CT sign in patients with acute abdominal pain. Radiographics. 2004;24(3):703-715.

11. Hu YY, Cohen HL, Scriven RJ. Picture of the month. Omental infarction. Arch Pediatr Adolesc Med. 2007;161(8):773-774.

12. Rimon A, Daneman A, Gerstle JT, Ratnapalan S. Omental infarction in children. J Pediatr. 2009;155(3):427-431.

13. Nubi A, McBride W, Stringel G. Primary omental infarction: conservative vs operative management in the era of ultrasound, computed tomography, and laparoscopy. J Pediatr Surg. 2009;44(5): 953-956.

14. Barai KP, Knight BC. Diagnosis and management of idiopathic omental infarction: a case report. Int J Surg. 2011;2(6):138-140.

15. Coulier B. Segmental omental infarction in childhood: a typical case diagnosed by CT allowing successful conservative treatment. Pediatr Radiol. 2006;36(2):141-143.
Pediatric Health, Medicine and Therapeutics

\section{Publish your work in this journal}

Pediatric Health, Medicine and Therapeutics is an international, peerreviewed, open access journal publishing original research, reports, editorials, reviews and commentaries. All aspects of health maintenance, preventative measures and disease treatment interventions are addressed within the journal. Practitioners from all disciplines are invited to submit

\section{Dovepress}

their work as well as healthcare researchers and patient support groups. The manuscript management system is completely online and includes a very quick and fair peer-review system. Visit http://www.dovepress.com/ testimonials.php to read real quotes from published authors. 